\title{
Understanding Human-Animal Relations in the Context of Primate Conservation: A Multispecies Ethnographic Approach in North Morocco
}

\author{
Siân Waters ${ }^{\mathrm{a}, \mathrm{b}}$ Sandra Bell ${ }^{\mathrm{a}} \quad$ Joanna M. Setchell ${ }^{\mathrm{a}}$ \\ aDepartment of Anthropology, Durham University, Durham, UK; ${ }^{b}$ Barbary Macaque \\ Awareness and Conservation, Tétouan, Morocco
}

\section{Keywords}

Human-animal relations - Primate conservation - Barbary macaque - Macaca sylvanus $\cdot$ Domestic dog $\cdot$ African wolf $\cdot$ Morocco

\begin{abstract}
Strategies for conserving species threatened with extinction are often driven by ecological data. However, in anthropogenic landscapes, understanding and incorporating local people's perceptions may enhance species conservation. We examine the relationships shepherds, living on the periphery of the mixed oak forest of Bouhachem in northern Morocco, have with animals in the context of a conservation project for Barbary macaques (Macaca sylvanus). We analyse ethnographic data to provide insights into shepherds' conceptions of Barbary macaques and the species which bring the shepherds into the forest - goats (Capra hircus), domestic dogs (Canis lupus familiaris), and the African wolf (Canis lupus lupaster). We interpret these data within the framework of boundary theory. Our multispecies ethnographic approach illuminates the different and, in the case of the domestic dog and the Barbary macaque, complex ways shepherds perceive each species. Some shepherds show intrinsic interest in the macaques, revealing potential recruits to conservation activities. As with any ethnographic study, our interpretations of human-animal relations in Bouhachem may not extrapolate to other areas of the Barbary macaque's distribution because of the unique nature of both people and the place. We recommend that conservationists examine complex place-based relations between humans and animals to improve wildlife conservation efforts.
\end{abstract}

\begin{tabular}{l}
\hline KARGER @ 2018 S. Karger AG, Basel \\
$\begin{array}{l}\text { E-Mail karger@karger.com } \\
\text { www.karger.com/fpr }\end{array}$
\end{tabular}

\author{
Siân Waters \\ Department of Anthropology \\ Durham University, Lower Mountjoy \\ South Road, Durham DH1 3LE (UK) \\ E-Mail sianwaters@gmail.com
}




\section{Introduction}

The social, cultural, political, historical and symbolic meanings people attribute to an animal species, whether domestic or wild, shape the way in which people perceive and treat that species [Richards, 2000; Costa et al., 2013; Goldman et al., 2013; Pooley et al., 2017]. Human-animal relations differ considerably across societies and among cultural contexts within societies [Marvin, 2000; Milton, 2000; Watson and Huntington, 2008; Baynes-Rock, 2013]. In particular, local people's conceptions (ontologies) of and relationships with wildlife can diverge considerably from those of conservationists [Milton, 2000; Adams, 2007; Aiyadurai, 2016; Leblan, 2016]. The conservationists' failure to understand diverse views has led to misunderstandings and clashes with the very people with whom conservationists need to engage [Milton, 2000; Theodossopoulos, 2003; Bell et al., 2008; Saunders, 2011]. This has led to calls for western conservationists to broaden their outlook by adopting an alternative cultural lens [Peterson et al., 2010]. Understanding how people perceive a species of conservation concern can lead to the development of conservation approaches more attuned to local perceptions, making these approaches more holistic and more effective in fostering a positive human-wildlife interface and inspiring people to participate in conservation activities [Kuriyan, 2002; McLennan and Hill, 2012; Costa et al., 2013; D'Lima et al., 2014].

Wildlife and domestic livestock coexist in many areas, so understanding people's perceptions of both categories of animals may have important implications for conservation strategy [Goldman et al., 2010]. Coexistence with wildlife can be problematic, particularly if wildlife threatens people's livelihoods. How people react to wildlife is, in many cases, particular to a place and developed and maintained by complex social, cultural and political issues, with some species drawn into "webs of human significances" [Pooley et al., 2017, p. 517]. Multispecies ethnography can examine a "shifting assemblage of agentive beings" [Ogden et al., 2013, p. 6] to further our understanding of how people and animals "co-shape each other's world" [Baynes-Rock, 2013, p. 210].

A multispecies ethnographic approach can serve to highlight the constructed metaphorical boundaries employed to separate humans from nature in western culture [Knight, 2003; Ogden et al., 2013]. Postmodernist anthropologists argue that such metaphorical boundaries are not culturally universal so fail to feature in explanations of many people's natural and social worlds [Descola, 1996; Corbey, 2005]. In some cultures, people use religion to strengthen the culturally constructed boundaries they deploy [Douglas, 1966; Ingold, 1980]. Despite these metaphorical boundaries, some wild and domestic species do not fit easily into rigid categories due to conflicting associations with different spaces or spheres. These species are described as anomalous [Douglas, 1966; Serpell, 1995; Knight, 2000]. Some animals, for example primates, possess particular characteristics that make them hard to categorise [Hill and Webber, 2010]. Such ambiguity causes problems in the maintenance of strict boundaries between animal and human, and thus primates are more likely to become stigmatised than other species [Douglas, 1966; Nyanganji et al., 2010]; in other words, primates are regarded as occupying spaces betwixt and between human and animal realms - they are liminal. Much effort has been expended in western culture to emphasise people's distance from primates while simultaneously recognising human characteristics in them [Corbey, 2005].

The perceptions of people who live alongside wild primates can vary greatly and can often explain why a primate may be persecuted in one culture and tolerated in 
another [Knight, 2003; Lee and Priston, 2005; Hill and Webber, 2010; Peterson and Riley, 2017]. Primates have negative historical and political resonance for some people and negative religious connotations for others [Richards, 2000; Costa et al., 2013; Baker et al., 2014]. In some cultures, humans have been enthusiastic in distancing themselves from other primates [Ohnuki-Tierney, 1987; Corbey, 2005] while elsewhere, primates are revered as deities [Saraswat et al., 2015].

At the location of the study we report on here, people are predominantly Muslim, and their ideas about animals may be influenced by Islamic ideas and practices. In Islam, the metamorphosis of people into primates and pigs (Sus sp.) after incurring God's displeasure endowed these animals with harām (forbidden) status and made them unfit for consumption due to their status as degraded humans [Cook, 1999]. In contrast, the goat (Capra hircus) and other cloven-hoofed ruminants meet the criteria necessary for consumption by followers of Islam, although the slaughter of ruminants must follow particular rituals to give the meat the halal (permissible) status that renders it edible [Boyazoglu et al., 2005]. The Prophet Mohamed did not tolerate dogs (Canis lupus familiaris) and deemed all canids to be harām. As a result, Muslims generally avoid physical contact with dogs and often show intense hostility towards them, although the only mention of the dog in the Qur'ann is positive [Foltz, 2006]. Dog saliva is a subject of concern in Islam, with various cleansing rituals performed if the saliva comes into contact with a person or a receptacle used for eating [Foltz, 2006]. The emphasis given to different species in Islam could influence people's relations with those species and how they perceive them, which may have implications for the conservation of such species. One of these species may be the Barbary macaque (Macaca sylvanus).

The Barbary macaque is now only present in fragmented populations in Morocco and Algeria and has become the focus of conservation attention as a result of its declining numbers [Fa et al., 1984; Camperio-Ciani and Mouna, 2006] and Endangered status [Butynski et al., 2008]. Threats to Barbary macaques include deforestation and habitat degradation, unmanaged primate tourism, and poaching for the illegal pet trade [Fa et al., 1984; Marechal et al., 2011; Maibeche et al., 2015; van Uhm, 2016]. The Barbary macaques' distribution in the southern Mediterranean has led to its presence in trade between different cultures and countries for thousands of years [Goudsmit and Brandon-Jones, 2000]. Osteological remains of Barbary macaques have been discovered in a Roman fort in Yorkshire, UK [Massetti and Bruner, 2009], and mummified in an Egyptian tomb [Goudsmit and Brandon-Jones, 1999], and the petrified body of a juvenile Barbary macaque has been found in the Italian city of Pompeii [Bailey et al., 1999]. Despite this evidence of a long-term human-Barbary macaque relationship, there are currently no ethnographic studies of people's perceptions of the Barbary macaque in its North African distribution.

In 2009, we initiated an inclusive, place-based conservation project to improve prospects for Barbary macaques in Bouhachem forest in the north of Morocco. The Barbary macaque shares the forest with other wildlife species in Bouhachem, and shepherds accompany some of their domestic animals into the forest during daylight hours. Here, we present ethnographic data to examine shepherds' views of domestic goats, domestic dogs, the African wolf (Canis lupus lupaster) and the Barbary macaque. The domestic goat is relevant to Barbary macaque conservation because the goats' nutritional needs bring the shepherds into the forest, and the animals are important to local people for economic reasons. Domestic dogs protect the goats from 


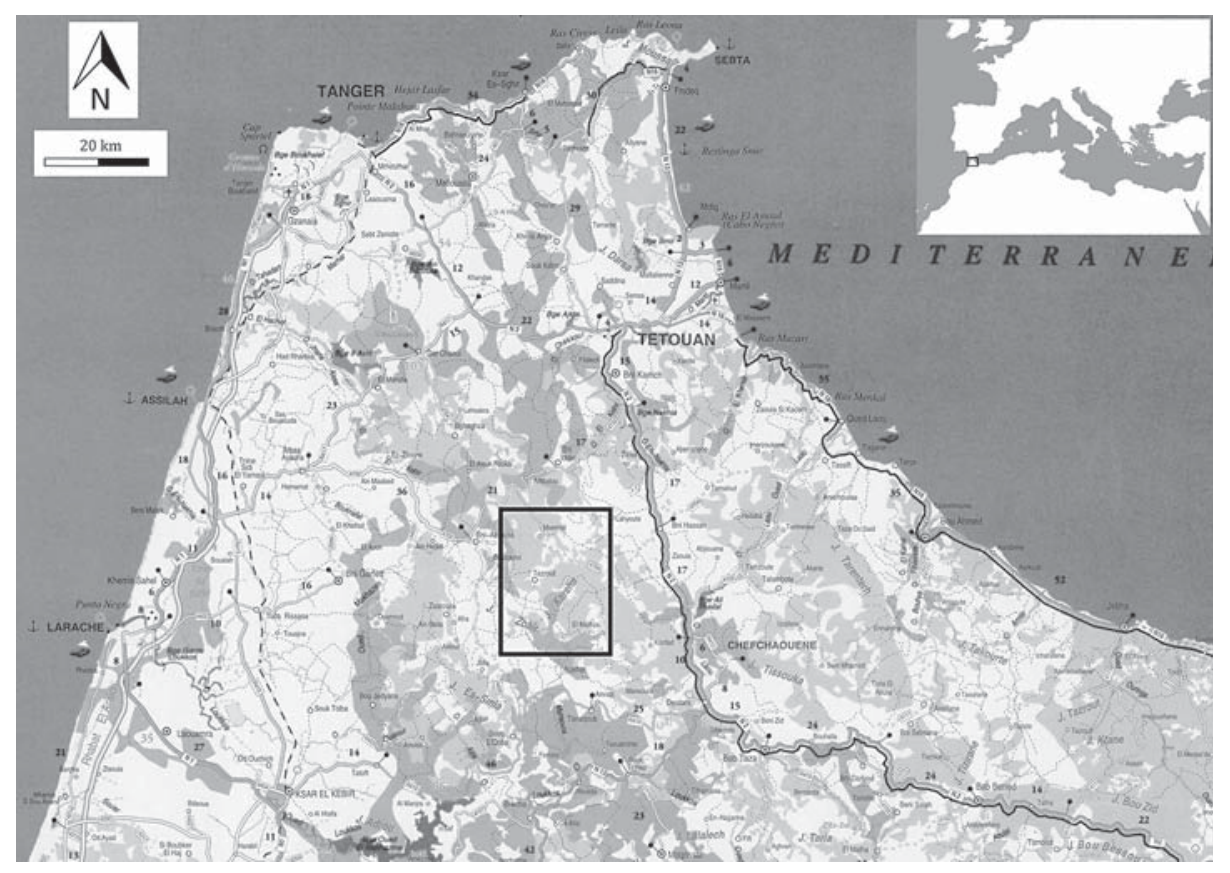

Fig. 1. The location of Jebel Bouhachem Nature Reserve (SIBE) in northern Morocco and the Mediterranean. The author and the publisher have made every effort to obtain permission for this Figure. Any omissions are entirely unintentional. The publisher would be pleased to hear from anyone whose rights have been unwittingly infringed.

the African wolf but also harass and kill Barbary macaques, possibly negatively influencing infant macaque mortality [Waters et al., 2017]. This study contributes to our understanding of the importance of human-animal relations for conservation by placing the focal species, the Barbary macaque, in the context of shepherds' conceptions of other wild and domestic species using the same habitat.

\section{Study Site}

Jebel Bouhachem Nature Reserve is approximately $142 \mathrm{~km}^{2}$ of mixed oak forest in a remote mountainous area of north Morocco (Fig. 1), reaching an altitude of 1,681 $\mathrm{m}$. The forest was comprehensively exploited by commercial logging companies during the Spanish occupation of the Rif between 1927 and 1956 [Mikesell, 1960; El Abdellaoui, 1999] and has since regenerated. Bouhachem is included in the Intercontinental Biosphere Reserve of the Mediterranean and is a component of the protected area network under the management of the Haut Commissariat aux Eaux et Forêts et à la Lutte contre la Désertification (HCEFLCD). The predominant language is Arabic, and the people are Sunni Muslims. Ten villages are situated on the periphery of the forest. We refer to these villages as the study villages or communities. There has been no recent census at a household level so no population data are available. The remote location of the villages means that their inhabitants have been historically marginalised and excluded from decisions concerning the forest they use to sustain their 
livelihoods as well as being discriminated against by city dwellers [Waters, 2014]. Most people in the area are agropastoralists, keeping goats and cows (Bos taurus). Cows graze in the forest unattended but goats are herded actively and regularly into and out of the forest. Goat numbers vary and depend on the size and wealth of the family.

Boys in the villages begin work as full-time shepherds from the ages of 8 to 14 years, often leaving school to do so because they are perceived by their parents to be more useful tending goats. Full-time shepherding continues until a man prepares to marry at around the age of 25-30 years. After he is married, a man spends his time in the village working the land and caring for his family, with only occasional shifts as a shepherd. Shepherding is a low status and physically demanding job, and shepherds are generally not paid for their labours if they are tending the family's herd. Some men return to shepherding when they are over 50 years old if their children have left the area and they have no grandsons to tend the goats. In general, shepherds, accompanied by livestock-guarding dogs, take the goats out to pasture in the mountains at around 9 a.m. every morning depending on weather conditions, and return them to the villages just before dusk, which varies from 4 to 7 p.m., depending on the time of year [Waters, 2014]. Livestock-guarding dogs are not well trained and harass and kill Barbary macaques in the forest [Waters et al., 2017]. During our research, some shepherds told us that they had killed macaques when they were younger. They admitted that this had been for sport rather than due to any conflict with the animals [Waters et al., in preparation].

\section{Methods}

Study participants were men aged 14-84 years working as shepherds regularly or occasionally at the time of the study. We interviewed 5 shepherds from each of the 10 villages on the periphery of Bouhachem forest. We encountered many of these individuals regularly while conducting Barbary macaque surveys in the forest. During the study, we rented a house in 1 village and visited the other 9 study villages at least once every 8 weeks (weather permitting) to familiarise people with our presence. Thus, when we began work in a new area of the forest the shepherds greeted us as a familiar presence and were very positive and relaxed about being interviewed.

We present data from semi-structured and open-ended interviews and participant observation. We collected interview data from March to November 2010 with the aim of coproducing information about the distribution of Barbary macaques in Bouhachem [Waters, 2014; Setchell et al., 2017]. These preliminary interviews were semi-structured enabling interviewees to communicate their depth of knowledge and their thoughts about the subject matter in their own words [Huntington, 1998; Drury et al., 2011]. Most interviews were conducted with one interviewee but occasionally other shepherds participated. Our interview focused on the shepherds' knowledge of the macaque's locations. However, many shepherds spontaneously expressed their beliefs and views about Barbary macaques and other species. We collected additional data from open-ended interviews during further engagement with 22 shepherds aged 14-84 years in the period 2011-2013. We had previously interviewed all these shepherds in 2010.

The primary investigator, S.W., spoke little Arabic and conducted the interviews via a research assistant and translator (A.). We recorded all semi-structured interviews. S.W. and A. transcribed the interviews once a week. We translated the interviews into English and discussed the translation to check for accuracy using an Arabic/English dictionary when necessary. However, it is possible that we lost some information or nuance in translation. Our analysis thus follows an iterative grounded approach where we identify emerging themes based on the qualitative data, as opposed to identifying them beforehand [Tadie and Fischer, 2013]. To do this, S.W. ex-

Understanding Human-Animal Relations in the Context of Primate Conservation
Folia Primatol 2018;89:13-29 DOI: $10.1159 / 000480079$ 
plored each transcript during the data collection phase, noting emerging themes which she placed in broad coded categories relating to the species discussed. She also annotated transcripts for less common themes such as the religious status of primates [Newing, 2011]. S.W. then coded the data systematically using the software programme NVIVO 8.

In addition to interviews, we observed shepherds' behaviour with their dogs and goats for intervals of 10-60 min. Anthropologists use such participant observation to observe human behaviour on a day-to-day basis with the aim of describing and explaining the social and cultural contexts and motivations for people's activities [Newing, 2011]. For the purposes of this study, we observed the shepherds' behaviour with their dogs and goats. We conducted these observations opportunistically making longer observations when the goats rested and ruminated. We never saw shepherds interacting with the macaques during our observations.

At the start of each interview we asked each shepherd if he would like to participate in the study. Nobody refused. All participants remain anonymous unless they indicated otherwise. This project gained approval from the Research Ethics and Data Protection Committee of the Department of Anthropology, Durham University, in spring 2009.

\section{Results and Interpretation}

\section{The Domestic Goat}

Our interviews revealed that the majority of households in the villages around Bouhachem owned goats, in varying numbers. Many shepherds freely admitted that they did not know the exact number of goats in their herd and that they had lost goats to predators in the past. Shepherds in Bouhachem were often responsible for 100 or more animals, and shepherds from 2 villages in Bouhachem often took herds of more than 300 goats over long distances through rocky, heavily forested areas. These large herds required the efforts of many shepherds as the animals were spread out over very wide pastures and thus vulnerable to predation and to getting lost. Indeed, we once returned a group of over 30 goats forgotten or lost in the forest by shepherds from 1 village. One shepherd voiced his concern about losing goats:

If you are in the forest you are always worried because the goats go in different directions and don't travel as a herd so you must guide them to try and keep them together. (Anon, 22, El Marzha)

We observed that the shepherds spent a great deal of energy and time keeping the goats moving together. The goats also dictated where and when the shepherds could rest and eat. Although the goats had favoured places where they rested and ruminated, they did not always settle in these places. Even if the shepherds had begun eating, they had little choice but to accompany the goats as they moved off. We never saw shepherds beat goats, but they did throw stones and branches at the herd in an attempt to influence their direction of travel.

Despite a ready market for goat meat during religious festivals, most shepherds were reluctant to sell animals for slaughter. This reluctance may stem from the villagers' perception of their goat herds as a symbol of their financial security. For example, one villager told us:

If you have goats then you have money. If you don't have goats then you don't have money. (Anon, Lahcene)

However, villagers reported that it was becoming difficult to find boys or young men to undertake the arduous work of shepherding. Younger shepherds were easily 
distracted while in the mountains and some admitted they only knew when they had lost a goat if the owner protested or they found it dead. Practising Muslims cannot eat goats that are killed and left by a predator as the meat is classed as carrion and is therefore harām.

The villagers in Bouhachem generally took good care of their goats. Goat kids were kept in the family household and allowed to enter the domestic quarters until they were around 6 weeks old and judged able to keep up with the herd when it was taken into the mountains. If goat kids were born while the nanny was grazing in the mountain pastures, the shepherd carried them himself so they did not fall prey to predators. Some people seemed much attached to their goats and alluded to them sentimentally:

If you lose a goat it's like you've lost a member of the family. (Anon, 57, El Marzha)

As noted elsewhere in Mediterranean ethnography, goats are valued for their usefulness and must "earn their keep" [du Boulay, 1974; Theodossopoulos, 2003]. In Bouhachem, as elsewhere, goats were commonly used by poorer people as a form of investment and sold to obtain cash for unforeseen circumstances such as family illness [Peacock et al., 2005]. However, as Theodossopoulos [2003] has pointed out in his work on Greek villagers' relationships with their domestic animals, their feelings about their charges are not easily categorised into utilitarian and non-utilitarian dichotomies. For the shepherds of Bouhachem, the goats were a source of income or wealth, but some people were also emotionally attached to their goats. Therefore, goats represented more than just the material wealth of a family, and protecting the goats from predators in the forest was important to the older shepherds.

\section{The African Wolf}

Bouhachem shepherds worried about potential predation on their animals by wild carnivores, sharing this preoccupation with many pastoralists and ranchers globally [Espuno et al., 2004; Bangs et al., 2005; Dickman et al., 2014]. There are several carnivore species in Bouhachem but the African wolf loomed largest in the minds of the shepherds. Most shepherds perceived the wolf to be a major predator of livestock in Bouhachem, and the wolves were such a major and daily preoccupation for the shepherds that their routes and resting places in the forest were determined by the animal's potential presence. A shepherd aged 27 from El Marzha told us:

There are places in the forest that are closed [where secondary vegetation is thick and difficult to penetrate for people] and there might be wolf there, so we like the marjas [forest clearings] where we can keep an eye on the goats and where we can eat our meal in peace.

A shepherd changed his route if there had been a recent attack on goats by the African wolf in an area he normally used. For example, the same shepherd told us:

If a wolf has attacked goats in an area we don't go to that site until 2-3 days have passed.

Shepherds also refrained from ascending the mountains if low-lying cloud hindered visibility because they believed these conditions allowed the wolf to attack the goats more easily. Despite listening to the older shepherds' tales of wolf predation, very young shepherds were not truly cognisant of the reality of life as a shepherd until they got distracted in the forest and lost their goats. Reality hit when they found bloody evidence of their neglect in the form of a predated goat which they tended to assume had been killed by a wolf rather than a dog. One shepherd called the wolf "our 
teacher," explaining that young shepherds needed to lose goats to the wolf at least once so they understood that shepherding was a serious responsibility, rather than a game. One shepherd seemed to acknowledge the wolf's role in teaching young shepherds to mind their herds when he implied that bad husbandry could have been to blame for some losses saying:

It's a good thing that the wolf is around because boys tend their animals more carefully. Many boys do not know that they have lost a goat until they find its remains in the forest the next day.

Shepherds apprehended and comprehended the wolf in their own distinct way, describing it as a "dangerous enemy" which "needs to be controlled," but also according it a grudging respect. A shepherd's ability to protect his goats from the wolf initiated him on his path to becoming a useful contributor to household wealth. The wolf had serious consequences for families' livelihoods and for men's identity and reputation as shepherds. The wolf and its predatory behaviour was thus a challenge to a man's identity as a shepherd, and possibly used as an excuse for goat losses which may have been attributable to a shepherd's lack of care. Like the red fox (Vulpes vulpes) in the UK, the wolf is what Marvin [2000] describes as "a rival competing with human interests" (p. 205) predating on goats that rightfully belonged to and should be killed by people.

\section{The Domestic Dog}

Dogs were regarded as ritually unclean by most people in Bouhachem. Villagers used the domestic dog to guard livestock and rarely shared a close relationship with dogs. Dogs were only accepted in public spaces as working animals and were not allowed in the domestic space of the house. When out in the forest, we often observed shepherds kicking and throwing stones at dogs saying that they were "dirty" and too close to people so might contaminate them. Shepherds did not name their dogs, and they found it very amusing that our dogs had names.

Shepherds perceived canine aggression as favourable, as it was the dogs' job to defend goat herds from humans and wild animals. For example, shepherds encouraged livestock-guarding dogs to pursue and kill wolves. Within the village boundary, however, shepherds severely punished village dogs which exhibited aggression towards humans. One dog was beaten so badly by his owner for aggression that he lost a hind leg. It was quite common for young, inexperienced dogs to kill a goat whilst out with the herd. These dogs were killed immediately by the shepherd even if they were not his own. Thus, dogs were killed because they turned from protector to predator and exhibited wild behaviour while dwelling within human boundaries.

Despite the dog's importance as a livestock guard, shepherds did not selectively breed from individuals which showed particular aptitude for protecting goats against the wolf. Dogs started to accompany the herds to the forest from around 3 months of age and were trained "by an older dog which teaches them their job" (according to one shepherd). These young dogs' immaturity, as well as their inadequate training, explained their failure to protect the herd against the wolf or their propensity to be easily distracted by other wildlife, including the macaques:

I see the dogs bothering the macaques for half an hour and a wolf could come and eat a goat whilst they are away. (Anon, 27 years, El Marzha)

During the study period, shepherds from 5 villages reported losing livestock to a dog pack in the forest. The shepherds said that these dogs came from the nearby 
large town. The shepherds usually referred to these dogs as "devils" and reported that the animals also killed wildlife including the macaques. We report our observation of dogs hunting and killing Barbary macaques elsewhere [Waters et al., 2017]. The shepherds perceived these dogs as feral and categorised them, like the wolf, as illegitimate killers. All the men agreed that the feral dogs were in good condition. One shepherd told us:

They are fit like the wild boar, because they eat [wild] boar, monkeys and cows. (Anon, 78, Tazrout)

We photographed 67 dogs, both with shepherds and ranging unaccompanied in the forest, and used these photographs to identify and connect the majority of dogs to their home village. We also made ad hoc observations of 3 packs of dogs leaving their home villages, entering nearby forest and showing hunting behaviour. Our photographs showed that all but 3 of the dogs we observed in 2010 were owned by people from villages around Bouhachem. Only 3 dogs appeared to be living feral in the forest. These dogs were in very poor health and disappeared in the winter of 2010.

Our observations conflicted with the shepherds' belief that the dogs observed hunting in the forest were feral. Like Italian farmers, who rarely acknowledged domestic dog predation on livestock, often blaming the European wolf (Canis lupus) [Ciucci and Boitani, 1998], the Bouhachem shepherds were reluctant to blame village dogs for livestock predation. We suggest the shepherds failed to recognise village dogs because they did not view dogs as individuals. In addition, they blamed the presence of the feral dogs on people from the nearby town, thus absolving themselves of any responsibility for feral dogs' behaviour. Dogs had little value to people and were easily replaceable. The lack of care and attention that dogs received from shepherds may have increased the dogs' need to enter the forest to predate on livestock, macaques, and other wildlife.

Shepherds often demonstrated hostility towards their dogs in Bouhachem. Scholars suggest that this hostility is inspired by the dog's close relationship to the wolf giving it potential to revert to "wild" behaviour, along with its existence on both sides of the metaphorical boundary in relation to humans [Douglas, 1966; Serpell, 1995]. The relationship between people and their dogs in Bouhachem was also seriously affected by the dog's position in Islam as harām. The domestic dog moved freely between village and forest, being neither truly wild nor truly domestic, but liminal, occupying a world spanning both wild and domestic spheres. We suggest that it is the dog's liminality which explains the differing treatments it received for aggressive behaviour in wild or human space in Bouhachem. The shepherds' relationship with their dogs was also ambiguous in that they appeared to resent the dog's presence whilst accepting its necessity as a protector of livestock. The position of dogs in Bouhachem village society mirrors the position of dogs elsewhere, existing symbolically "between the human and non-human worlds" [Serpell, 1995, p. 254].

\section{The Barbary Macaque}

All the shepherds we interviewed told us they had obtained their knowledge of Barbary macaque locations from their own observations, rather than acquiring the information from other people. This suggests that information about macaques was not considered interesting or valuable enough to share. Local folklore featuring Barbary macaques also appeared to be absent among the shepherds of Bouhachem, suggesting that the species was of little cultural importance in local communities. 
Drawing attention to the Barbary macaque among shepherds resulted in mixed reactions. When we began to talk about the macaques with groups of men they often found the topic amusing and compared one another to macaques. For example:

My brother [pointing at an individual in the group] climbs trees like a macaque!

When $\mathrm{A}$ is angry he shouts like a big male macaque [speaker does an impersonation of a macaque alarm calling]. (Anon, 22, Remla)

However, a different picture emerged when we interviewed shepherds individually. On such occasions, some men alluded to the metamorphic status of primates in the Qur'ān:

They were humans before so it's not good to bother them. (Anon, 25, Afertane)

Macaques can see well but they don't have a good sense of smell because they used to be people so they are similar to people. They have five fingers and five toes on each hand. They have a beard like a man and the little ones are like human babies. (Anon, 74, Adrou)

The shepherds alluded to the macaques' religious metamorphosis from human to animal but did not appear to view it negatively. This is reminiscent of the views of animist people sharing habitat with chimpanzees (Pan troglodytes verus) in Guinea Bissau who believe that chimpanzees were previously human but transgressed local moral codes and were changed into chimpanzees by a supernatural power [Costa et al., 2013].

When chatting to us by themselves, shepherds of all age groups talked positively about the macaques, alluding to their human-like physical attributes, and viewing them as sociable and family-oriented. For example:

They are the people of this forest. (Anon, 27, Adrou)

They live as if they are in a village. (Anon, 28, Lahcene)

There are no animals that feel such a lot for their young as macaques do. (Anon, 74, Adrou)

A macaque had lost its baby and when she found it again she hugged it like a mother hugs her baby. They are just like a family, just like us. (Anon, approx. 40, Almidene)

In our study, shepherds' ideas about macaques reflect the ambivalence detectable elsewhere in the traditional Islamic views of primates [Kruk, 1995] where the Barbary macaque appears to occupy a metaphorical borderland where clear categorisation is difficult. The shepherds alluded to this situation themselves when they compared the macaques' behaviour to that of people. Many shepherds dealt with their difficulty and unease concerning the anomalous position of the macaque by using ridicule to make a clear division between them. As in Bouhachem, mockery has also been used in Japanese culture to create a firm dividing line between people and primates [OhnukiTierney, 1987]. Shepherds who were positive about the animals did not voice these opinions when in the presence of their peer group for fear of ridicule.

When we asked shepherds how they would feel if the macaques disappeared altogether from the forest, the majority expressed disbelief that this could happen. However, when a few shepherds imagined such a scenario they responded thus:

If I went to places I usually saw them [the macaques] and didn't see them I would feel lonely. (Anon, 28, Lahcene)

No more? I would feel that the mountain is empty like a bottle of water without the water. (Anon, 34, Remla) 
The shepherds' disbelief that the macaques could ever disappear from the forest contrasts with conservationists' concerns about the general decline in the species. Most shepherds were unaware that Barbary macaques have a limited geographical distribution. For example, 12 individuals asked S.W. why she had travelled to Morocco to find out about macaques when she could study them at home. The shepherds' belief reflects findings from other studies showing that communities sometimes assume that the species they share space with, and often encounter, are plentiful [Shaffer et al., 2017] or common everywhere [Abd Mutalib et al., 2013]. The shepherds were correct in their assumption that Barbary macaques are abundant in Bouhachem, which has the largest group sizes currently recorded in Morocco [Waters et al., 2015], but the situation is less positive in other areas of the species' distribution [El Alami et al., 2013; Menard et al., 2013]. Such contrasting information for species which are still apparently plentiful but whose overall distribution has decreased substantially can lead to conflict between scientists and local communities with the latter feeling their knowledge is discounted because it is perceived as inferior or inaccurate [Gilchrist et al., 2005; Dowsley and Wenzel, 2008].

When we asked shepherds how they felt when they saw the macaques, some found nothing noteworthy about their encounters, while others enjoyed them. Replies varied from:

It's all the same to me whether I see them or not - they are just there in the forest. If I see them I carry on with my work, I don't have time to watch them. (Anon, 60, Talajamine)

to: Slalem)

I like seeing the macaques. If I don't see them it's like I am missing something. (Anon, 19,

Not all shepherds appreciated the macaques, but we encountered men who viewed the macaques positively. A love of the natural world is not universal [Milton, 2002] but individuals who view themselves as being connected with nature are more likely to exhibit conservation behaviour [Schultz, 2001; Lokhorst et al., 2014].

\section{Discussion and Conservation Implications}

As Knight [2003] has pointed out, the emphasis on nature-culture, and thus human-animal difference, and its influence on the western conception of boundaries and their maintenance between humans and animals can obscure the far greater complexity of human-animal interactions in diverse ecological and cultural settings. Our placebased study of species important to Moroccan shepherds provided us with extremely useful insights into how they viewed multiple species and how these perceptions influenced Barbary macaque conservation. Disaggregating the relationships shepherds had with these 4 species, as we have here, reveals their complex, diverse and dynamic interconnections. Shepherds' relationships with goats and the African wolf were uncomplicated, relating directly to one species' role as prey and the other's as predator. The shepherds' obsession with the wolf reflected their concern about the safety of their goats in the wild space of the forest. Both species had a direct effect on shepherds' behaviour the wolf influenced the movements of the shepherds in the forest whilst the goats' need to ruminate dictated where and when the shepherds were able to rest.

Understanding Human-Animal Relations in the Context of Primate Conservation
Folia Primatol 2018;89:13-29 DOI: $10.1159 / 000480079$ 
Religion can, and does, affect shepherds' views of different species, as demonstrated here by the inferior position of the domestic dog in the shepherds' world view. The reality of such perceptions was illustrated by the contemptuous and often violent way shepherds treated dogs, despite their utility as livestock protectors. The dog acted as mediator against the effects of a wild canid, the African wolf, although it is unclear whether the shepherds understood the relationship between the species. Both canids preyed on livestock, as well as on the Barbary macaque, but shepherds classified dogs that did this as feral. Our observations and photographs placed these dogs as village dogs, but communicating this information to shepherds without privileging our knowledge over theirs presented its own set of problems.

We endeavoured to resolve the difficulty in communicating this knowledge by developing a dog health programme to vaccinate dogs against rabies (which kills people and livestock in the area) and tacitly communicate their ownership status by providing owners with coloured collars for their dogs [Waters, 2014; Setchell et al., 2017]. We were successful in communicating ownership status [Waters, 2014], and recent research suggests that shepherds are attempting to control their male dogs' behaviour by castrating them to prevent them roaming [Watson, 2015].

Shepherds' understandings of the macaque revealed some ambiguity where the dualist categories of humans and animals, nature and culture are indivisibly entwined. The macaques appeared to have no utilitarian value as they were not eaten or sold as pets. In some areas, religious tenets appear to protect certain primate species, even those perceived as agricultural pests [Baker et al., 2014; Saraswat et al., 2015]. However, despite the religious belief expressed by some shepherds in this study that the macaques are "degraded humans" and as such unfit for human consumption, no participant mentioned any taboos against killing macaques. The absence of such a taboo and of any local folklore pertaining to the macaque suggests that the species did not occupy an important position in society. Indeed, some shepherds told us that prior to meeting us they killed macaques for fun when they encountered them in the forest suggesting that religious influence is relatively weak among this group [Waters, 2014]. The apparent absence of folklore or taboos forbidding the killing of primates is not necessarily an impediment to their conservation. For instance, despite the apparent absence of either primate folklore or taboos regarding their killing, Mestizo subsistence farmers in Belize tolerate the crop-raiding behaviour of Yucatan spider monkeys (Ateles geoffroyi yucatanensis) [Waters, pers. observation], and Brazilian subsistence farmers do not kill bearded capuchins (Sapajus libidinosus) for feeding on their cultivars [Spagnoletti et al., 2016].

The attribution of anthropomorphic qualities to Barbary macaques by many shepherds echoes that of people sharing their environment with non-human primates elsewhere [Nyanganji et al., 2010; Costa et al., 2013; Baker et al., 2014; Ellwanger et al., 2015] and may improve primate conservation prospects. For example, apparent empathy with a primate species may discourage people from killing the Guizhou snubnosed monkey (Rhinopithecus brelichi) in China [Ellwanger et al., 2015] and Sclater's monkey (Cercopithecus sclateri) in Nigeria [Baker et al., 2014]. Sharing information about the macaques' social behaviour and infant care is an important part of our conservation message to inspire empathy towards the animals in village children around Bouhachem. We aim to reduce the embarrassment and ridicule surrounding the macaques which we encountered among shepherds and schoolchildren. In our lesson, we first share information about the macaques and then we all make macaque masks. The 
children take a little while to relax but when the conservation team begins wearing the masks the children begin to participate fully, and many children wear the masks for days after. After these lessons, many children approach us happily to tell us about their observations of macaques in the forest and shepherds often tell us how much the children enjoyed the lessons and what they learned.

Our sharing of information with the shepherds and village children while linking their "place" in Bouhachem with the Barbary macaque's unique status as the only North African primate made some men view the animals differently and to develop a sense of pride in the species. Six months into our study it became possible to discuss the macaques among groups of shepherds with individuals sharing their macaque observations with us and their companions. Our engagement and information sharing gave shepherds confidence and a safe space to express their interest in Barbary macaques.

Some shepherds with an intrinsic interest in the macaques began to take a lead in protecting the animals. For example, when a shepherd encountered a group of boys persecuting macaques, he intervened and expressed his disapproval. He told us:

I found a group of shepherd boys who had caught an infant [macaque] and were playing with it. I was angry with them as I know these macaques are special and we must all look after them, not hurt them. (Anon, 28, Slalem)

Such individuals are now playing an indispensable role in increasing positive perceptions of the macaques. Identifying and, in some cases, employing such individuals (when funding permits) has been an important step in our inclusive conservation programme.

Bouhachem shepherds' perceptions of the Barbary macaque may differ significantly from shepherds sharing space with Barbary macaques elsewhere over their distribution. For example, in the Middle Atlas Mountains, habituated macaque groups act as tourist attractions and regular poaching of infant macaques for the illegal pet trade occurs [Marechal et al., 2011, 2016; van Uhm, 2016]. The macaques' utilitarian role as revenue generators in the Middle Atlas suggests that people-macaque relations there may diverge considerably from those of shepherd-macaque relations in Bouhachem. The precarious situation of the macaques in the Middle Atlas is directly related to anthropogenic activities [Menard et al., 2013, 2014]. We strongly suggest that research regarding how different stakeholders view macaques and their perceptions of present and past macaque conservation activities should be undertaken as a priority to ensure the development of effective conservation interventions to prevent further declines in this population.

Mismatches between the perceptions of local people and conservationists have been found for several primate species [Knight, 1999; Saunders, 2011; Baker et al., 2014]. The conservationists' omission of local people's perceptions of primates and other species in conservation strategy may lead to inappropriate targeting of education and awareness programmes and/or community conservation initiatives, which may result in wasted conservation effort or even failure. We found that reflecting on and understanding the diverse ways shepherds viewed the macaques and other animals provided us with increased insight, contributing substantial value when applied to the development of community conservation initiatives. We strongly recommend that conservationists working with primates take the time to recognise and elucidate complex human-animal relations at their study sites to facilitate their conservation efforts. 


\section{Acknowledgements}

We are indebted to the shepherds of Bouhachem engaging with us and assisting us with our research and conservation work. We thank the Haut Commissariat aux Eaux et Forêts et la Lutte contre la Désertification for granting our research permits and University Abdelmalek Essâadi, Tétouan, for assistance with our permit applications. S.W. thanks the Royal Zoological Society of Scotland for supporting her doctoral research 2009-2012. For present and past support of our research and conservation work, we are extremely grateful to: International Technical Assistance Committee, Department of the Interior, USA; Association Française des Parcs Zoologiques; Association Beauval Nature; Conservatoire pour la Protection des Primates France; Tiergarten Schönbrunn, Austria; Folly Farm, UK; GaiaZoo, the Netherlands; Parco Natura Viva, Italy; Zoo Helsinki, Finland; Blair Drummond Safari Park, UK; Primate Society of Great Britain, UK; International Primatological Society, UK; Alameda Wildlife Conservation Park, Gibraltar; NatureZoo Rheine, Germany; Apenheul Primate Park, the Netherlands; Zoo Barcelona, Spain; International Primate Protection League, USA; Mohamed Bin Zayed Endangered Species Fund. We are grateful to Kerry McAuliffe Dore, Sherrie Alexander, Lucy Radford, and 2 anonymous reviewers for comments on an earlier version of this manuscript.

\section{Disclosure Statement}

We understand Folia Primatologica's declaration of interests, and we declare we have no competing interests.

\section{References}

Abd Mutalib AH, Fadzly N, Foo R (2013). Striking a balance between tradition and conservation: general perceptions and awareness level of local citizens regarding turtle conservation efforts based on age factors and gender. Ocean \& Coastal Management 78: 56-63.

Adams WM (2007). Thinking like a human: social science and the two cultures problem. Oryx 41: 275276.

Aiyadurai A (2016). “Tigers are our brothers": understanding human-nature relations in the Mishmi Hills, Northeast India. Conservation \& Society 14: 305-316.

Bailey JF, Henneberg M, Colson IB, Ciarallo A, Hedges REM, Sykes B (1999). Monkey business in Pompeii - unique find of a juvenile Barbary macaque skeleton in Pompeii identified using osteology and ancient DNA techniques. Molecular Biology and Evolution 16: 1410-1414.

Baker LR, Olubode OS, Tanimola AA, Garshelis DL (2014). Role of local culture, religion, and human attitudes in the conservation of sacred populations of a threatened "pest" species. Biodiversity and Conservation 23: 1895-1909.

Bangs EE, Fontaine JA, Jimenez MD, Meier TJ, Bradley EH, Niemeyer CC, Smith DG, Mack CM, Asher V, Oakleaf JK (2005). Managing wolf-human conflict in the northwestern United States. In People and Wildlife: Conflict or Coexistence? (Woodroffe R, Thirgood JV, Rabinowitz A, eds.), pp 340-356. Cambridge, Cambridge University Press.

Baynes-Rock M (2013). Life and death in the multispecies commons. Social Science Information/Sur Les Sciences Sociales 52: 210-227.

Bell S, Hampshire K, Tonder M (2008). Person, place and knowledge in the conservation of the Saimaa ringed seal. Society and Natural Resources 21: 277-293.

Boyazoglu J, Hatziminologlou I, Morand-Fehr P (2005). The role of the goat in society: past, present and perspectives for the future. Small Ruminant Research 60: 13-23.

Butynski TM, Cortes J, Waters S, Fa JE, Hobbelink ME, van Lavieren E, Belbachir F, Cuzin F, de Smet K, Mouna M, de Longh H, Menard N, Camperio-Ciani A (2008). Macaca sylvanus. The IUCN Red List of Threatened Species 2008: e.T12561A3359140. http://dx.doi.org/10.2305/IUCN.UK.2008.RLTS. T12561A3359140.en.

Camperio-Ciani A, Mouna M (2006). Human and environmental causes of the rapid decline of Macaca sylvanus in the Middle Atlas of Morocco. In The Barbary Macaque: Biology, Management and Conservation (Hodges JK, Cortes J, eds.), pp 257-275. Nottingham, Nottingham University Press. 
Ciucci P, Boitani L (1998). Wolf and dog depredation on livestock in central Italy. Wildlife Society Bulletin 26: 504-514.

Cook M (1999). Ibn Qutayba and the monkeys. Studia Islamica 89: 43-74.

Corbey R (2005). The Metaphysics of Apes: Negotiating the Animal-Human Boundary. Cambridge, Cambridge University Press.

Costa S, Casanova CCN, Sousa C, Lee P (2013). The good, the bad and the ugly: perceptions of wildlife in Tombali (Guinea-Bissau, West Africa). Journal of Primatology 2: 110.

D’Lima C, Marsh H, Hamann M, Sinha A, Arthur R (2014). Positive interactions between Irrawaddy dolphins and artisanal fishers in the Chilika Lagoon of Eastern India are driven by ecology, socioeconomics and culture. Ambio 43: 614-624.

Descola P (1996). Constructing natures: symbolic ecology and social practice. In Nature and Society: Anthropological Perspectives (Descola P, Palsson G, eds.), pp 82-102. London, Routledge.

Dickman AJ, Hazzah L, Carbone C, Durant SM (2014). Carnivores, culture and "contagious conflict": multiple factors influence perceived problems with carnivores in Tanzania's Ruaha landscape. Biological Conservation 178: 19-27.

Douglas M (1966). Purity and Danger: An Analysis of Concepts of Pollution and Taboo. London, Routledge.

Dowsley M, Wenzel G (2008). "The time of the most polar bears": a co-management conflict in Nunavut. Arctic 61: 177-189.

Drury R, Homewood K, Randall S (2011). Less is more: the potential of qualitative approaches in conservation research. Animal Conservation 14: 18-24.

Du Boulay J (1974). Portrait of a Greek Mountain Village. Oxford, Oxford University Press.

El Abdellaoui MC (1999). Explotacion de los recursos naturales. In Espana en Marruecos (Nogue J, Villanova JL, eds.), pp 511-550. Lleida, Editorial Milenio.

El Alami A, van Lavieren E, Aboufatima R, Chait A (2013). A survey of the Endangered Barbary macaque Macaca sylvanus in the Central High Atlas Mountains of Morocco. Oryx 47: 451-456.

Ellwanger AL, Riley EP, Niu KF, Tan CL (2015). Local people's knowledge and attitudes matter for the future conservation of the Endangered Guizhou snub-nosed monkey (Rhinopithecus brelichi) in Fanjingshan National Nature Reserve, China. International Journal of Primatology 36: 33-54.

Espuno N, Lequette B, Poulle ML, Migot P, Lebreton JD (2004). Heterogeneous response to preventive sheep husbandry during wolf recolonization of the French Alps. Wildlife Society Bulletin 32: 11951208.

Fa JE, Taub DM, Menard N, Stewart PJ (1984). The distribution and current status of the Barbary macaque in North Africa. In The Barbary Macaque: A Case Study in Conservation (Fa JE, ed.), pp 79-111. London, Plenum Press.

Foltz RC (2006). Animals in Islamic Tradition and Muslim Cultures. Oxford, Oneworld Publications.

Gilchrist G, Mallory M, Merkel F (2005). Can local ecological knowledge contribute to wildlife management? Case studies of migratory birds. Ecology and Society 10: 20.

Goldman MJ, Roque de Pinho J, Perry J (2010). Maintaining complex relations with large cats: Maasai and lions in Kenya and Tanzania. Human Dimensions of Wildlife 15: 332-346.

Goldman MJ, Roque de Pinho J, Perry J (2013). Beyond ritual and economics: Maasai lion hunting and conservation politics. Oryx 47: 490-500.

Goudsmit J, Brandon-Jones D (1999). Mummies of olive baboons and Barbary macaques in the Baboon Catacomb of the Sacred Animal Necropolis at North Saqqara. Journal of Egyptian Archaeology 85: $45-53$.

Goudsmit J, Brandon-Jones D (2000). Evidence from the Baboon Catacomb in North Saqqara for a West Mediterranean monkey trade route to Ptolemaic Alexandria. Journal of Egyptian Archaeology 86: 111-119.

Hill CM, Webber AD (2010). Perceptions of nonhuman primates in human-wildlife conflict scenarios. American Journal of Primatology 72: 919-924.

Huntington HP (1998). Observations on the utility of the semi-directive interview for documenting traditional ecological knowledge. Arctic 51: 237-242.

Ingold T (1980). Hunters, Pastoralists and Ranchers. Cambridge, Cambridge University Press.

Knight J (1999). Monkeys on the move: the natural symbolism of people-macaque conflicts in Japan. The Journal of Asian Studies 58: 622-647.

Knight J (2000). Introduction. In Natural Enemies: People-Wildlife Conflicts in Anthropological Perspective (Knight J, ed.), pp 1-35. London, Routledge.

Knight J (2003). Waiting for Wolves in Japan. Oxford, Oxford University Press.

Kruk R (1995). Traditional Islamic views of apes and monkeys. In Ape, Man, Apeman: Changing Views since 1600 (Corbey R, Theunissen B, eds.), pp 29-41. Leiden, Department of Prehistory of Leiden University.

Kuriyan R (2002). Linking local perceptions of elephants and conservation: Samburu pastoralists in northern Kenya. Society and Natural Resources 15: 949-957.

Understanding Human-Animal Relations in the Context of Primate Conservation
Folia Primatol 2018:89:13-29 DOI: $10.1159 / 000480079$ 
Leblan V (2016). Territorial and land-use rights perspectives on human-chimpanzee-elephant coexistence in West Africa (Guinea, Guinea-Bissau, Senegal, nineteenth to twenty-first centuries). Primates 57: 359-366.

Lee PC, Priston NEC (2005). Human attitudes to primates: perceptions of pests, conflict and consequences for primate conservation. In Commensalism and Conflict: The Human-Primate Interface (Paterson JD, Wallis J, eds.), pp 1-23. Winnipeg, Hignell Printing.

Lokhorst AM, Hoon C, le Rutte R, de Snoo G (2014). There is an I in nature: the crucial role of the self in nature conservation. Land Use Policy 39: 121-126.

Maibeche Y, Moali A, Yahi N, Menard N (2015). Is diet flexibility an adaptive life trait for relictual and peri-urban populations of the Endangered primate Macaca sylvanus? PLoS One 10: e0118596.

Marechal L, Semple S, Majolo B, MacLarnon A (2016). Assessing the effects of tourist provisioning on the health of wild Barbary macaques in Morocco. PLoS One 11: 0155920.

Marechal L, Semple S, Majolo B, Qarro M, Heistermann M, MacLarnon A (2011). Impacts of tourism on anxiety and physiological stress levels in wild male Barbary macaques. Biological Conservation 144: 2188-2193.

Marvin G (2000). The problem of foxes: legitimate and illegitimate killing in the English countryside. In Natural Enemies: People-Wildlife Conflicts in Anthropological Perspective (Knight J, ed.), pp 189211. London, Routledge.

Massetti M, Bruner E (2009). The primates of the western Palearctic: a biogeographical, historical and archaeozoological review. Journal of Anthropological Sciences 87: 33-91.

McLennan M, Hill CM (2012). Troublesome neighbours: changing attitudes towards chimpanzees (Pan troglodytes) in a human-dominated landscape in Uganda. Journal for Nature Conservation 20: 219227.

Menard N, Foulquier A, Vallet D, Qarro M, Le Gouar P, Pierre JS (2013). How tourism and pastoralism influence population demographic changes in threatened large mammal species. Animal Conservation 17: 115-124.

Menard N, Rantier Y, Foulquier A, Qarro M, Chillasse L, Vallet D, Pierre J-S, Butet A (2014). Impact of human pressure and forest fragmentation on the Endangered Barbary macaque Macaca sylvanus in the Middle Atlas of Morocco. Oryx 48: 276-284.

Mikesell MW (1960). Deforestation in North Morocco. Science 132: 441-448.

Milton K (2000). Ducks out of water: nature conservation as boundary maintenance. In Natural Enemies (Knight J, ed.), pp 229-246. London, Routledge.

Milton K (2002). Loving Nature: Towards an Ecology of Emotion. London, Routledge.

Newing H (2011). Conducting Research in Conservation: A Social Science Perspective. Abingdon, Routledge.

Nyanganji G, Fowler A, McNamara A, Sommer V (2010). Monkeys and apes as animals and humans: ethnoprimatology in Nigeria's Taraba region. In Primates of Gashaka: Socioecology and Conservation in Nigeria's Biodiversity Hotspot (Sommer V, Ross C, eds.), pp 101-134. New York, Springer.

Ogden LA, Hall B, Tanita K (2013). Animals, plants, people and things: a review of multispecies ethnography. Environment and Society: Advances in Research 4: 5-24.

Ohnuki-Tierney E (1987). The Monkey as Mirror. Princeton, Princeton University Press.

Peacock C, Devendra C, Ahuya C, Roets M, Hossain M, Osafo E (2005). Goats. In Livestock and Wealth Creation (Owen E, Jayasuriya N, Smith T, eds.), pp 361-385. Nottingham, Nottingham University Press.

Peterson JV, Riley EP (2017). Sacred monkeys? An ethnographic perspective on macaque sacredness in Balinese Hinduism. In Ethnoprimatology: A Practical Guide to Research at the Human-Nonhuman Primate Interface (Dore KM, Riley EP, Fuentes A, eds.), pp 206-218. Cambridge, Cambridge University Press.

Peterson RB, Russell D, West P, Brosius JP (2010). Seeing (and doing) conservation through cultural lenses. Environmental Management 45: 5-18.

Pooley S, Barua M, Beinart W, Dickman A, Holmes G, Lorimer J, Loveridge AJ, Macdonald DW, Marvin G, Redpath S, Sillero-Zubiri C, Zimmermann A, Milner-Gulland EJ (2017). An interdisciplinary review of current and future approaches to improving human-predator relations. Conservation Biology 31: 513-523.

Richards P (2000). Chimpanzees as political animals in Sierra Leone. In Natural Enemies (Knight J, ed.), pp 78-103. London, Routledge.

Saraswat R, Sinha A, Radhakrishna S (2015). A god becomes a pest? Human-rhesus macaque interactions in Himachal Pradesh, northern India. European Journal of Wildlife Research 61: 435-443.

Saunders F (2011). It's like herding monkeys into a conservation enclosure: the formation and establishment of the Jozani-Chwaka Bay National Park, Zanzibar, Tanzania. Conservation \& Society 9: 261273.

Schultz PW (2001). Assessing the structure of environmental concern: concern for self, other people, and the biosphere. Journal of Environmental Psychology 21: 1-13. 
Serpell JA (1995). The Domestic Dog: Its Evolution, Behaviour and Interactions with People. Cambridge, Cambridge University Press.

Setchell JM, Fairet EFM, Shutt K, Waters S, Bell S (2017). Biosocial conservation: integrating biological and ethnographic methods to study human-primate interactions. International Journal of Primatology 35: 401-426.

Shaffer CA, Milstein M, Yukuma C, Marawanaru E, Suse P (2017). Sustainability and comanagment of subsistence hunting in an indigenous reserve in Guyana. Conservation Biology 31: 1119-1131.

Spagnoletti N, Cardoso TCM, Fragaszy D, Izar P (2016). Coexistence between humans and capuchins (Sapajus libidinosus): comparing observational data with farmers' perceptions. International Journal of Primatology 38: 243-262.

Tadie D, Fischer A (2013). Hunting, social structure and human-nature relationships in Lower Omo, Ethiopia: people and wildlife at a crossroads. Human Ecology 41: 447-457.

Theodossopoulos D (2003). Troubles with Turtles: Cultural Understandings of the Environment on a Greek Island. New York, Berghahn Books.

Van Uhm D (2016). Monkey business: the illegal trade in Barbary macaques. Journal of Trafficking, Organised Crime and Security 2: 36-49.

Waters S (2014). Including People in Primate Conservation: A Case Study of Shepherds and Barbary Macaques in Bouhachem Forest, North Morocco. PhD thesis, Durham University.

Waters S, El Harrad A, Chetuan M, Amhaouch Z (2015). Barbary macaque group size and composition in Bouhachem forest, North Morocco. African Primates 10: 53-56.

Waters S, El Harrad A, Chetuan M, Bell S, Setchell JM (2017). Dogs disrupting wildlife: domestic dogs disturb and kill Barbary macaques in Bouhachem forest, North Morocco. African Primates 12: 5558 .

Watson A, Huntington OH (2008). They're here - I can feel them: the epistemic spaces of indigenous and western knowledges. Social \& Cultural Geography 9: 257-281.

Watson T (2015). Perceptions of Dogs by Shepherds in Bouhachem, Northern Morocco. MSc thesis, Southampton University..

Understanding Human-Animal Relations in the Context of Primate Conservation
Folia Primatol 2018;89:13-29 DOI: $10.1159 / 000480079$ 